\title{
Apresentação de denúncias sobre acessibilidade de serviços de governo eletrônico por pessoas com deficiência: uma análise à luz da Teoria do Comportamento Planejado
}

\section{Presentation of denouncements about accessibility of electronic government services by disabled people: an analysis in the light of the Planned Behavior Theory}

\author{
Monique S. S. Siqueira ${ }^{1}$; André P. Freire ${ }^{2}$ \\ ${ }^{1}$ - Universidade Federal de Lavras (UFLA) - Lavras, MG, Brasil. \\ ${ }^{2-}$ Universidade Federal de Lavras (UFLA) - Lavras, MG, Brasil. *orientador \\ moniquescalco@gmail.com, apfreire@dcc.ufla.br
}

\begin{abstract}
This work sought to understand the factors that influence the behavioral intent of people with disabilities in relation to the presentation of complaints in the control and control over accessibility barriers in government portals, based on the Theory of Planned Behavior. For this, the author carried out a triangulation of methods, through interviews with people with disabilities and with prosecutors, and application of questionnaires to people with disabilities. The study brought important results to show the importance of raising the awareness of people with disabilities about their rights in the use of digital systems, and about the use of means of inspection and filing complaints.
\end{abstract}

\begin{abstract}
Resumo. Este trabalho buscou compreender os fatores que influenciam a intenção de comportamento de pessoas com deficiência em relação à apresentação de denúncias sobre barreiras de acessibilidade em portais governamentais, com base na Teoria do Comportamento Planejado. Para isso, foi realizada uma triangulação de métodos, por meio de entrevistas com pessoas com deficiência e com promotores de justiça, e aplicação de questionários as pessoas com deficiência. O estudo trouxe resultados relevantes para mostrar a necessidade de aumentar a conscientização de pessoas com deficiência sobre seus direitos no uso de sistemas digitais, e sobre a utilização dos meios de fiscalização e apresentação de denúncias.
\end{abstract}

\section{Introdução}

O termo governo eletrônico surgiu no final da década de 90 e tem crescido rapidamente nos últimos anos. Conforme definição das Nações Unidas, o governo eletrônico se refere a utilização das Tecnologias de Informação e Comunicação (TICs) pela administração pública com o objetivo de facilitar e integrar fluxo de trabalhos e processos, gerenciar dados e informações, assim como aperfeiçoar o fornecimento de serviços públicos e ampliar canais de comunicação para engajamento da sociedade. Pode-se dizer que o governo eletrônico é um instrumento para promover uma administração melhor e mais eficiente e que tem crescido rapidamente nos últimos anos (UNITED NATIONS, 2014; 


\section{UNITED NATIONS, 2016).}

Porém, para que o governo eletrônico possa garantir efetivamente uma administração pública melhor e mais eficiente, é preciso que existam instrumentos que promovam o acesso e a disponibilidade das TICs aos cidadãos. A administração pública precisa ser sensível em relação às necessidades da população em geral, em particular aqueles que podem ser afetados por algum tipo de exclusão, como pessoas com deficiência, as quais são o foco deste estudo. Desse modo, é imprescindível que as informações e serviços disponíveis nos portais governamentais sejam acessíveis a todos, independente de deficiências ou tecnologias utilizadas para realizar a navegação.

Ressalta-se a elevada quantidade de pessoas com deficiência no Brasil. Conforme o último censo realizado pelo Instituto Brasileiro de Geografia e Estatística (IBGE, 2010), considerando a população residente no país, $23,9 \%$ da população brasileira possui pelo menos uma das deficiências investigadas: visual, auditiva, motora e intelectual.

Nesse sentido, Thacher (2002) define acessibilidade Web como a expectativa de que todo usuário, utilizando qualquer agente (software ou hardware) possa interagir com o conteúdo Web. Consoante à Web Accessibility Iniciative (WAI), a acessibilidade Web está relacionado à condição do usuário em compreender, navegar, interagir e contribuir com o conteúdo Web.

A fim de nortear a elaboração de portais acessíveis foram criados padrões de acessibilidade, os quais fornecem um conjunto de recomendações que visam atender aos diferentes tipos de deficiências e limitações. O WCAG (Web Content Accessibility Guidelines) (W3C, 2018), atualmente em sua versão 2.1, é a principal referência mundial no que se refere à acessibilidade Web (LAZAR; GOLDSTEIN; TAYLOR, 2015). No Brasil foi instituído o e-MAG (Modelo de Acessibilidade de Governo Eletrônico) (BRASIL, 2014) em 2007 como referência de acessibilidade para serviços de governo digital. Destarte, diversas leis foram criadas determinando a obrigatoriedade de sistemas de comunicação e informação serem acessíveis a todos. Destaca-se a Convenção Internacional dos Direitos Humanos da ONU, da qual o Brasil é signatário, bem como a Lei Brasileira de Inclusão, a Lei $\mathrm{N}^{\circ}$ 13.146, de 6 de julho de 2015.

No entanto, mesmo com todas as obrigações legais e com as diretrizes de acessibilidade, observa-se a persistência das barreiras de acessibilidade em portais governamentais. Desse modo, a questão da acessibilidade e inclusão digital está entre os Grandes Desafios em Interação Humano-Computador no Brasil.

No Brasil, em levantamento realizado pelo Comitê Gestor da Internet (CGI.br, 2010), constatou-se que $98 \%$ das páginas de domínios .gov.br não respeitam os padrões de acessibilidade do Modelo de Acessibilidade em Governo Eletrônico (e-MAG) do governo brasileiro, sendo que apenas $2 \%$ apresentam algum tipo de conformidade mesmo com os critérios considerados mais elementares, uma vez que o estudo só envolveu avaliações feitas por ferramentas automáticas. Ademais, estudos recentes afirmam que ainda há evidências de falta de observação dos critérios de acessibilidade pelos sítios do governo (CARVALHO; CAGNIN; PAIVA, 2017; OLIVEIRA; ELER, 2015; MAIA, 2015). Esse fato se deve, em partes, à falta de fiscalização e denúncias da sociedade. Isso porque as leis não são autoexecutáveis, sendo necessário instrumentos de execução (LAZAR; GOLDSTEIN; TAYLOR, 2015).

O papel de fiscalização no Brasil é exercido por órgãos como o Ministério Público, 
instituição responsável pela defesa da ordem jurídica, do regime democrático e dos interesses fundamentais. Tendo em vista esse cenário de falta de acessibilidade em portais governamentais, é fundamental que a sociedade tenha conhecimento do papel exercido pelo Ministério Público e sobre o caminho para denunciar essas ilicitudes para provocar sua atuação. A partir dessas denúncias, o Ministério Público pode tomar as medidas cabíveis e fazer valer os direitos de acessibilidade Web previstos em lei. No entanto, evidências preliminares apontam a inexistência de denúncias sobre problemas de acessibilidade em sítios do governo ao Ministério Público ou às próprias ouvidorias.

Tendo em vista esse cenário, o principal objetivo deste trabalho é identificar os fatores que influenciam a intenção de pessoas com deficiência em relação à fiscalização e apresentação de denúncias ao Ministério Público de barreiras de acessibilidade aos serviços públicos na Web, tendo como base a Teoria do Comportamento Planejado (TCP). Para a TCP, as atitudes, normas subjetivas e controle comportamental percebido ensejam na formação da intenção. Em regra, quanto mais favorável a atitude e a norma subjetiva e quanto maior o controle percebido, mais forte a intenção comportamental se demonstra e maior a probabilidade do comportamento se concretizar (AJZEN, 2002). Diante disso, os autores buscaram analisar qual a influência das atitudes, normas subjetivas e controle comportamental na intenção de comportamento de denúncia de pessoas com deficiência.

Para atingir este objetivo, foi realizada uma triangulação de métodos, quais sejam: 1- Pesquisa documental, em que foi investigado como tem sido as práticas de denúncias e fiscalização da acessibilidade de serviços públicos de governo eletrônico pela população com deficiência; 2- Entrevistas com 5 pessoas com deficiência e 3 promotores do Ministério Público de Minas Gerais de duas cidades do sul de Minas Gerais que atuam na defesa dos direitos das pessoas com deficiência; 3 - Aplicação de questionário que foi respondido por 134 pessoas com deficiência de distintos estados brasileiros.

\section{Trabalhos relacionados}

Nesta seção são apresentados alguns trabalhos que utilizaram a TCP para compreender o comportamento de denúncia. Os trabalhos apresentados nesta seção retratam distintos contextos, sendo que não foi encontrado qualquer trabalho sobre comportamento de denúncia de pessoas com deficiência em relação à falta de acessibilidade.

Seifert (2016), em sua tese de doutorado, utilizou a TCP para investigar os construtos emocionais e racionais que preveem as intenções dos estudantes universitários em se envolver em comunicação interpessoal sobre sexualidade e a comunicação interpessoal sobre agressão sexual.

Natan, Hanukayev e Fares (2011) investigaram os fatores que influenciam os enfermeiros de hospitais israelenses em relatar a violência cometida contra eles no local de trabalho, com base na TCP.

East (2000) investigou os principais fatores associados à reclamação de clientes em ambiente de varejo, tendo como base a TCP.

Feng e Wu (2005) investigaram os fatores associados à intenção dos enfermeiros em relatar suspeita de abuso infantil em Taiwan e determinar a adequação empírica da TCP estendida para explicar a intenção das enfermeiras nesse sentido. 
Baldridge e Veiga (2001) analisaram os fatores que influenciam a pessoa com deficiência a requerer seu direito de acomodação razoável em ambiente de trabalho, tendo como base os preceitos estabelecidos na Americans with Disabilities Act. Os autores utilizaram alguns elementos da TCP e outras teorias para a realização do estudo.

\section{Procedimentos metodológicos}

Para atingir o objetivo proposto, foi realizada uma triangulação de métodos. Diante disso, a pesquisa compreendeu as seguintes etapas:

- Pesquisa documental, em que foi investigado como tem sido as práticas de denúncias e físcalização da acessibilidade de serviços públicos de governo eletrônico pela população com deficiência ao Ministério Público de Minas Gerais (MPMG). Os dados coletados são referentes às denúncias realizadas ao MPMG no primeiro semestre de 2016. A pesquisa foi realizada no diário oficial eletrônico a partir da busca pelo termo "pessoas com deficiência". Foram pesquisados todos os procedimentos processuais e extraprocessuais para a resolução de conflitos envolvendo denúncias de lesão a direitos de pessoas com deficiência ao Ministério Público.

- Entrevistas semiestruturada com pessoas com diferentes tipos de deficiência (três pessoas com deficiência visual e duas pessoas com deficiência física) com o objetivo de compreender os fatores que influenciam a intenção de comportamento de denúncia destes. Os entrevistados foram selecionados a partir da área de formação acadêmica ou atuação profissional. Foram realizadas entrevistas também com promotores do MPMG de duas cidades do sul de Minas que atuam na defesa dos direitos das pessoas com deficiência, com o intuito de analisar como tem sido a atuação desta instituição no que tange a defesa dos direitos de acessibilidade de pessoas com deficiência, sobretudo no que diz respeito a acessibilidade Web, bem como a percepção destes profissionais em relação à intenção de comportamento de denúncia de pessoas com deficiência. A análise de dados foi feita por meio da técnica de análise de conteúdo. Neste trabalho são mencionadas algumas falas dos entrevistados, as quais são caracterizadas pela abreviação PCD - pessoa com deficiência, e PJ - promotor de justiça e seus respectivos números.

- Utilização de survey, tendo como instrumento de coleta de dados o questionário, elaborado com base nas entrevistas e na TCP. O questionário foi aplicado a amostra maior de pessoas com deficiência a fim de produzir maior confiabilidade e validade à pesquisa, e obter dados quantitativos sobre os pesos dos fatores que mais influenciam a intenção de comportamento de denúncia. Os dados foram coletados a partir da aplicação de questionário composto por questões de múltipla escolha utilizando escala Likert (1932). Neste trabalho, adotou-se a variação de 1 a 5, com as seguintes opções: concordo totalmente; concordo; nem concordo, nem discordo; discordo; discordo totalmente. A partir dessas opções, os respondentes puderam manifestar o grau de concordância em relação a cada item. A amostra deste trabalho não foi limitada a local ou região, sendo extensiva a todo o país, a fim de obter uma ampla base de dados. O questionário contou com 134 respostas válidas, as quais foram analisadas descritivamente e na sequência, realizou-se a análise do modelo de equações estruturais mediante o software Smart PLS. Para realizar a análise de dados, foram estabelecidos 3 critérios de investigação, 
denominamos hipóteses, os quais foram criados de acordo com a TCP (AJZEN, 1985). A seguir são descritas as hipóteses que foram investigadas:

○ Hipótese 1 (H1): Atitudes influenciam positivamente na intenção de denúncia sobre problemas de acessibilidade em portais governamentais;

○ Hipótese 2 (H2): Normas Subjetivas influenciam positivamente na intenção de denúncia sobre problemas de acessibilidade em portais governamentais;

○ Hipótese 3 (H3): Controle Comportamental Percebido influencia positivamente na intenção de denúncia sobre problemas de acessibilidade em portais governamentais;

\section{Resultados e Discussão}

Esta seção apresenta o resultado dos três estudos realizados na dissertação.

\subsection{Análise das práticas de denúncias pela população com deficiência de barreiras de acessibilidade}

Em pesquisa realizada no diário oficial do MPMG, foram encontrados 1.146 denúncias envolvendo lesão a direitos de pessoas com deficiência. Todas as denúncias foram registradas para estudo comparativo entre questões relacionadas a denúncias sobre acessibilidade e demais denúncias. Do total de denúncias encontradas, 164 (14,31\%) tratam de problemas de acessibilidade. Essas denúncias são em sua maioria sobre barreiras arquitetônicas, transporte e urbanística, respectivamente. Observa-se que nenhuma denúncia sobre barreiras de acessibilidade Web foi encontrada.

Para complementar a pesquisa, em maio de 2018 foi enviado à Ouvidoria Geral da União solicitação de informação sobre a existência de manifestações versando sobre problemas de acessibilidade em serviços digitais públicos que impeçam ou dificultem o acesso aos referidos serviços por pessoas com deficiência ou que configurem violações a normas de acessibilidade. Em resposta, o órgão explicou que apenas 2 manifestações foram compatíveis com a solicitação. No entanto, ambas as reclamações foram enviadas pelos membros do Projeto de Extensão da UFLA chamado "Acessibilidade Digital”, do qual os autores fazem parte.

Diante disso, os resultados apontam evidências preliminares da inexistência de denúncias sobre problemas de acessibilidade em sítios do governo ao Ministério Público ou às próprias ouvidorias.

\subsection{Análise qualitativa: percepções dos entrevistados dos fatores que influenciam na intenção do comportamento de denúncia}

Aqui são apresentados os resultados obtidos com a realização das entrevistas com as pessoas com deficiência e promotores de justiça. Este estudo utilizou as variáveis da TCP como base para a definição das categorias. A partir da análise das entrevistas, foram definidas subcategorias que foram agrupadas dentro das categorias pertinentes, as quais são apresentadas no Quadro 1. 


\section{Quadro 1. Classificação dos fatores relacionados à intenção de denúncia de problemas de acessibilidade em sítios do governo.}

\begin{tabular}{|c|rl|}
\hline Categorias & \multicolumn{1}{|c|}{ Subcategorias } \\
\hline & $\bullet$ & Acesso \\
& $\bullet$ & Cultura \\
Atitudes & $\bullet$ & Efeito \\
\hline Normas Subjetivas & $\bullet$ & Influência das pessoas \\
\hline & $\bullet$ & Conhecimento de leis \\
& $\bullet$ & Conhecimento técnico e procedimental \\
Controle Comportamental & $\bullet$ & Consciência \\
Percebido & $\bullet$ & Conhecimento MP \\
& $\bullet$ & Formalismo \\
\hline
\end{tabular}

\subsubsection{Atitudes}

As atitudes são formadas a partir das crenças sobre o objeto da atitude e os relaciona a certos atributos. No caso das atitudes em relação ao comportamento, cada crença relaciona o comportamento a um resultado. O construto atitude, em relação ao comportamento se refere à avaliação positiva ou negativa realizada pelo indivíduo sobre determinado comportamento (AJZEN, 1985), ou seja, reflete a forma como a pessoa se sente perante um comportamento específico. A partir dessa categoria, criou-se três subcategorias: acesso, cultura e efeito, os quais são explicados a seguir.

\section{- Acesso}

Os entrevistados mencionaram que a intenção de comportamento de denúncia está relacionada ao fato de que os portais governamentais são pouco acessados por pessoas com deficiência. Desse modo, é incomum pessoas com deficiência lidar com problemas de acessibilidade nesses sítios. Os entrevistados observaram que quando as pessoas com deficiência se deparam com esses problemas, elas preferem recorrer ao auxílio de terceiros do que requerer formalmente a garantia dos seus direitos.

Não foram encontrados dados ou pesquisas confirmando a afirmação de que portais governamentais são pouco acessados por pessoas com deficiência. No entanto, uma possível explicação para esse fenômeno pode estar relacionado à própria falta de acessibilidade do governo eletrônico brasileiro, de forma que as pessoas com deficiência podem evitar acessá-lo. Outra possível explicação se refere ao fato de que as informações e serviços em sítios do governo não fazem parte do cotidiano das pessoas com deficiência, sendo acessados somente quando necessário (por exemplo, em época de declaração de imposto de renda em que as pessoas acessam o sítio da Receita Federal).

A questão da baixa frequência do acesso aos portais governamentais por pessoas com deficiência remete aos estudos sobre adoção de governo eletrônico, especificamente sobre a questão da facilidade de uso. Dentre os construtos mencionados na facilidade de uso, Carter e Bélanger (2004) destacam o quanto uma inovação é vista pelo adotante como 
relativamente difícil de usar e entender, sendo este um fator que pode influenciar na adoção de governo eletrônico. Assim, o fato dos sítios governamentais não serem acessíveis às pessoas com deficiência pode ser visto pelo adotante como um aspecto que dificulta a utilização da TIC, sendo um fator que influencia na questão do acesso aos sítios do governo.

\section{- Cultura}

Os entrevistados também mencionaram a falta de cultura combativa como um fator que influencia na intenção de comportamento de denúncia. De acordo com os entrevistados, as pessoas não buscam os meios oficiais para requerer o cumprimento de seus direitos. Muitas vezes as pessoas preferem buscar caminhos alternativos, como as redes sociais, para demonstrar a insatisfação.

O promotor de justiça PJ-02 explicou que a cultura de defesa dos direitos das pessoas com deficiência é relativamente recente, de modo que os direitos básicos das pessoas com deficiência, como educação e saúde por exemplo, ainda não são garantidos. Assim, a promoção do acesso aos meios de comunicação e informação não é percebido enquanto prioridade. As pessoas com deficiência ainda se deparam com desafios significativos no acesso aos direitos básicos. Nas entrevistas, todos relataram diversos problemas de acessibilidade, principalmente de natureza arquitetônica, urbanística e atitudinais.

Outrossim, de acordo com o promotor de justiça PJ-03, há uma mudança na postura da sociedade no tocante à reclamação, em que as pessoas em geral, e não somente as pessoas com deficiência, utilizam as redes sociais para manifestar a insatisfação. No entanto, o promotor observa que comumente esse instrumento não visa noticiar o fato de forma propositiva para a solução do problema. Para o promotor, este é um problema cultural, em que as pessoas efetuam reclamações como desabafo, ao invés de encaminhálas de uma forma propositiva visando à resolução do problema.

\section{- Efeito}

Essa subcategoria se refere as questões realizadas aos entrevistados que buscavam verificar se as pessoas acreditam que a realização de denúncia promove a resolução do problema. A maioria dos entrevistados (pessoas com deficiência) demonstrou descrença de que a denúncia promove mudanças ou melhorias em relação ao problema relatado. Os entrevistados demonstraram a percepção de que a denúncia somente é efetiva quando adquire publicidade ou quando é realizada por um amplo grupo de pessoas. Outro aspecto depreendido das entrevistas se refere à incredulidade no poder fiscalizatório e punitivo do Estado.

Alguns entrevistados afirmaram não acreditar na efetividade da denúncia tendo em vista experiências negativas ocorridas no passado. O entrevistado PCD-04, pessoa com deficiência visual, relatou que bateu com o rosto na lixeira porque a mesma estava com altura inadequada, não correspondendo aos padrões determinados pela legislação do município. O PCD-04 também mencionou situação em que um carro permaneceu estacionado sobre da faixa de pedestre durante 5 dias, impossibilitando sua travessia na faixa. O entrevistado informou que mesmo com sucessivas ligações à instituição competente, nenhuma medida foi tomada.

Em relação aos portais governamentais, três pessoas afirmaram que já se depararam com barreiras nesses sítios e que enviaram e-mail para o órgão do próprio sítio 
explicando o problema encontrado e solicitando a devida correção. Esse contato foi realizado por e-mail e nenhuma das manifestações foram atendidas. $\mathrm{O}$ entrevistado PCD04 também relatou situação em que, ao se deparar com problema de acessibilidade no sítio do Ministério da Ciência, Tecnologia, Inovações e Comunicações, enviou e-mail para diversos órgãos públicos, incluindo o próprio sítio do Ministério, contento o print da tela e explicações detalhadas, mas foi totalmente ignorado. Outro problema relatado pelo entrevistado PCD-05 diz respeito à dificuldade em realizar cursos oferecidos na plataforma virtual do MEC,em virtude da falta de acessibilidade do mesmo. $\mathrm{O}$ entrevistado comunicou ao órgão sobre o problema e não obteve qualquer resposta, sendo necessário interromper a realização do curso. Por esses motivos é que as pessoas com deficiência não acreditam na eficácia da denúncia.

Outras dificuldades foram relatadas, como a impossibilidade de entrar em lojas porque o degrau de acesso é muito alto, ou em ônibus por não conseguir subir a escada; falta de provadores adaptados; despreparo de vendedores para o atendimento de pessoas com deficiência; discriminação e comentários que levam a percepção de que a pessoa com deficiência é um problema, dentre tantos outros.

O entrevistado PCD-05 mencionou que é preciso mudar muito a política para acreditar na efetividade da denúncia. O mesmo entrevistado afirmou que está lutando há dois anos para alterar lei municipal que discorre sobre o direito da pessoa com deficiência ter gratuidade no transporte coletivo. Isso porque a atual lei (no momento da elaboração deste trabalho) prevê a gratuidade somente para pessoas com deficiência física, excluindo as pessoas com outras deficiências. O projeto de lei propondo que a gratuidade seja extensiva às pessoas com outros tipos de deficiência foi entregue à Câmara e não foi colocado em votação. Somente o entrevistado PCD-01 demonstrou acreditar na efetividade da denúncia. No entanto, é importante mencionar que essa pessoa trabalha no Ministério Público, o que possivelmente influenciou em sua resposta.

$\mathrm{O}$ efeito da denúncia foi apontado em outros estudos como um elemento de influência no comportamento de denúncia das pessoas. Esse resultado foi obtido no trabalho de Baldrige e Veiga (2001), os quais afirmaram que se o indivíduo tem a percepção de que a adequação no ambiente de trabalho é improvável, há uma grande probabilidade do indivíduo não realizar a solicitação, tendo em vista que o indivíduo se sente desencorajado frente a resistência de seus empregadores em efetuar o pedido. Uma suposição no presente trabalho é de que as pessoas com deficiência deixam de denunciar porque acreditam que a obtenção de melhorias ou mudanças em relação ao problema relatado é improvável, em consonância com resultados com o obtido no trabalho de Baldrige e Veiga (2001).

Ademais, experiências negativas ocorridas no passado em relação ao Estado, em que não houve qualquer ação do governo visando solucionar o problema relatado, podem ser um fator que influencia negativamente na realização de denúncia. Neste trabalho, supõe-se que se as pessoas com deficiência acreditam que a denúncia não promoverá um resultado satisfatório, a probabilidade de denúncia diminui sensivelmente, corroborando os resultados obtidos neste trabalho.

\subsubsection{Normas Subjetivas}

As normas subjetivas estão relacionadas à pressão social percebida para realizar ou não determinado comportamento. São agrupamentos das crenças normativas acessíveis 
relacionadas às expectativas daqueles que são tidos como referências importantes (AJZEN, 1991). Ajzen (2002) observa que as normas subjetivas são compostas por normas injuntivas e descritivas. As normas injuntivas se referem às percepções dos grupos de referência no que se refere à aprovação ou desaprovação do comportamento e o valor que o indivíduo atribui a essas percepções. Já as normas descritivas estão relacionadas a percepção de que os próprios grupos referência se envolvem no comportamento alvo e a motivação em executá-lo. A partir dessa categoria, foi criada a subcategoria influência das pessoas.

\section{- Influência das pessoas}

Nesta subcategoria de análise, os autores abordaram respostas a perguntas sobre o apoio das pessoas próximas, como família e amigos, em relação à realização de denúncia a fim de promover a garantia de seus direitos. A maioria dos entrevistados afirmou que as pessoas próximas geralmente apoiam e incentivam o comportamento de denúncia, sendo que um deles relatou que muitas vezes seus amigos e familiares tomam a iniciativa de denunciar. Apenas um entrevistado (PCD-04) declarou que a família não se manifesta a respeito. $\mathrm{O}$ entrevistado $\mathrm{PCD}-04$ acrescentou que acredita que ainda existem famílias que reprimem as pessoas com deficiência, por sentimento de medo, proteção ou até mesmo por vergonha. Outro aspecto mencionado nas entrevistas diz respeito ao medo de realizar denúncia, tendo em vista o receio de se indispor ou ser inconveniente.

De modo geral, quando as pessoas relevantes para o indivíduo acreditam que o mesmo deve realizar determinado comportamento, este perceberá a pressão social para executá-lo (AJZEN, 1985). Manning (2009) observa que a pressão social inevitavelmente afeta o comportamento das pessoas. Feng e Wu (2005) observaram que os enfermeiros que acreditavam que as outras pessoas queriam que eles reportassem a suspeita de abuso infantil se mostravam mais propensos ao comportamento de relatar o abuso. Baldridge e Veiga (2001) verificaram que a obrigação social percebida é maior quando o indivíduo acredita que as pessoas pensam que ele deve defender seus direitos. Isso pode ser explicado tendo em vista que o requerimento de acomodação razoável é visto enquanto uma continuação do ativismo na defesa dos direitos das pessoas com deficiência, os quais foram conquistados arduamente. Da mesma forma, a denúncia de problemas de acessibilidade em sítios do governo pode ser visto pela população com deficiência como uma forma de auxiliar pedidos futuros e dar sequência à conquista dos direitos das pessoas com deficiência.

\subsubsection{Controle Comportamental Percebido}

O comportamento, na maioria das vezes, depende não apenas do esforço individual investido, mas também do controle que o indivíduo exerce sobre outros fatores internos e externos (AJZEN, 1991). As crenças de controle estão relacionadas à presença ou ausência de recursos e oportunidades necessários para a realização de determinado comportamento. A partir dessa categoria, os autores criaram cinco subcategorias: conhecimento de leis, conhecimento técnico e procedimental, consciência, conhecimento Ministério Público e formalismo, os quais são detalhados a seguir.

\section{- Conhecimento de leis}

Nessa subcategoria de análise, os autores elencaram questões relacionadas ao conhecimento de leis que discorrem sobre o direito de acesso de pessoas com deficiência às TICs. Todos os entrevistados (pessoas com deficiência) responderam que conhecem 
seus direitos. No entanto, ao longo das entrevistas, os autores perceberam que os entrevistados tem um conhecimento limitado sobre as leis que tratam dessa temática. $\mathrm{O}$ entrevistado PCD-03 ressaltou que conhece as leis que estão mais próximas da sua realidade, ou seja, que afetam diretamente a sua vida, como a lei de cotas para pessoas com deficiência em concursos públicos. Dentre os aspectos mencionados por Ajzen (1985) que influenciam o comportamento humano, o autor menciona como fator interno as informações que o indivíduo possui sobre o assunto. Neste caso, os entrevistados demonstraram pouco conhecimento sobre legislação que determina que os sítios governamentais devem ser acessíveis, tampouco sobre a existência de diretrizes de acessibilidade.

\section{- Conhecimento técnico e procedimental}

Outro aspecto depreendido nas entrevistas se refere ao conhecimento técnico e procedimental. $\mathrm{O}$ conhecimento técnico diz respeito à capacidade do usuário de saber identificar que a dificuldade de navegar se trata de um problema de acessibilidade, bem como a habilidade de descrever o problema em uma denúncia. Destarte, a questão procedimental está relacionada ao desconhecimento sobre onde e como denunciar, o qual também foi mencionado nas entrevistas como um fator limitante.

A questão do desconhecimento técnico e procedimental pode estar relacionada à carência de divulgação e conscientização em relação às questões de acessibilidade Web. O promotor de justiça PJ-03 mencionou a importância de se propor a discussão desse tema, a fim de levar essa problemática ao conhecimento da sociedade. Isso também demonstra a necessidade de maior divulgação sobre o papel das instituições de controle e sobre como a população pode ter acesso a esses serviços.

\section{- Consciência}

A falta de consciência das pessoas com deficiência de que os problemas de acessibilidade às TICs são tão graves quanto qualquer outro problema de acessibilidade, também foi um fator mencionado nas entrevistas. Os autores observaram que as pessoas com deficiência têm uma tendência a se incomodar com barreiras arquitetônicas, atitudinais, transporte e urbanística, mas não percebem ou não se incomodam com os problemas de acessibilidade aos meios de comunicação. Essa informação remete aos dados coletados no diário oficial eletrônico do MPMG, que mostraram ausência de qualquer manifestação envolvendo sobre a questão da acessibilidade web. A questão da consciência também está relacionada com o aspecto cultural.

Outro aspecto abordado nas entrevistas diz respeito à necessidade de conscientização coletiva, a fim de expor publicamente que os problemas existem. $\mathrm{O}$ entrevistado PCD-04 afirmou que antes de ficar cego, não conhecia os problemas que uma pessoa com deficiência se depara diariamente. A pessoa que não tem deficiência e que não convive com alguém com deficiência, não tem contato direto e frequente com as problemáticas das pessoas com deficiência. Diante disso, é extremamente relevante promover a conscientização coletiva.

\section{- Conhecimento sobre o Ministério Público}

Os promotores acreditam que a falta de conhecimento das pessoas em relação às atribuições do Ministério Público pode ser um fator que limite a realização de denúncias. As pessoas desconhecem onde, como e para quem denunciar esse tipo de problema. Esse campo ainda é novo e desconhecido por eles. Dentre os principais âmbitos práticos de 
atuação do Ministério Público para a defesa dos direitos difusos e coletivos de pessoas com deficiência, destaca-se a fiscalização e implementação das condições de acessibilidade previstas sobretudo no Decreto $\mathrm{n}^{\circ} 5.296 / 04$ e posteriormente na Lei Brasileira de Inclusão, Lei $n^{\circ} 13.146 / 15$. Os promotores de justiça PJ-02 e PJ-03 afirmaram que o desconhecimento em relação a essa atribuição do Ministério Público está relacionada a inexistência de divulgação e publicidade a fim de orientar a população nesse sentido.

\section{- Formalismo}

Esse item está relacionado ao acanhamento em realizar denúncia em virtude do formalismo que existe no setor público. Existe a percepção de que a realização de denúncia envolve um processo moroso, trabalhoso e sem expectativas de êxito. Assim, o receio da burocracia e da morosidade desmotivam as pessoas a denunciar formalmente os problemas de acessibilidade. Outrossim, o promotor de justiça PJ-03 observa que a própria estrutura física dos locais, que demandam vestimenta formal para acesso ao Ministério Público ou ao fórum, às vezes inibe a participação da pessoa.

Essa questão do formalismo enquanto elemento que influencia na intenção de comportamento de denúncia também foi encontrada no trabalho de Natan, Hanukayev e Fares (2011). Os autores verificaram que os enfermeiros estão mais propensos a relatar a agressão sofrida verbalmente, por ser mais fácil e por levar menos tempo do que relatórios escritos. Uma possível explicação é que as pessoas com deficiência acreditam que os procedimentos na Administração Pública são morosos e pouco efetivos. Dessa forma, as pessoas acabam optando por outras soluções mais rápidas.

\subsection{Análise quantitativa: aplicação de questionário com pessoas com deficiência}

Nesta seção são apresentados os resultados da Modelagem de Equações Estruturais dos dados obtidos dos questionários respondidos por pessoas com deficiência, a qual buscou identificar o peso dos construtos analisados sobre a intenção de comportamento de denúncia de problemas de acessibilidade em portais governamentais.

Primeiramente, verificou-se o p-valor referente às hipóteses de que cada um dos construtos exerça influência na variável resposta de intenção comportamental. O p-valor trata do nível de significância, sendo comumente utilizado o valor de 5\% como limite máximo para indicar significância estatística (HAIR et al., 2017), o qual foi aplicado neste trabalho. Todos os construtos apresentaram níveis abaixo do limite.

Por conseguinte, foi verificado o NFI - índice de ajuste normado (do inglês, normed fit index), o qual assume valores entre 0 e 1 , sendo que um modelo com ajuste perfeito tem valor NFI igual a 1, mas acima de 0,90 são considerados com bom ajuste (HAIR et al., 2017). O NFI do modelo proposto neste trabalho foi de 0,577. Trata-se de valor abaixo do estabelecido pela literatura, mas por se tratar de pesquisa exploratória é considerado um valor aceitável.

Também foi verificado o peso de cada caminho $(\beta)$ das variáveis independentes em relação à variável dependente, sendo o peso de atitudes 0,221 , normas subjetivas 0,296 e controle comportamental percebido 0,318.

Por fim, foi analisado o coeficiente de determinação $\mathrm{R}^{2}$ para verificar a qualidade do ajuste do modelo (HAIR et al., 2017). O coeficiente $\mathrm{R}^{2}$ varia entre 0 e 1 , sendo que 
quanto maior o valor de $\mathrm{R}^{2}$, melhor a predição da variável dependente. No modelo proposto neste trabalho, existem três variáveis exógenas ou variáveis independentes (atitudes, normas subjetivas e controle comportamental percebido) e uma variável endógena ou variável dependente (intenção). Nesta pesquisa, o $\mathbf{R}^{2}$ do modelo foi de 0,366 , demonstrando que os construtos explicam em torno de $36 \%$ da intenção de denúncia de problemas de acessibilidade em sítios do governo.

\subsubsection{Estimação do Modelo de Caminhos}

Os dados foram exportados para o software SmartPLS, o qual possibilitou a organização dos dados de acordo com os construtos da TCP e elaboração do diagrama de caminhos. A Figura 1 representa o modelo, no qual foram estabelecidas as relações entre os construtos (representado pelos círculos) e suas respectivas variáveis medidas (representado pelos retângulos). Hair et al. (2017) observam a existência de dois tipos de relação entre os construtos: dependência e correlação. As setas retas presentes na Figura 1 demonstram as relações de dependência, ou seja, o impacto de um construto sobre o outro ou sobre uma variável. Assim, as setas direcionam o efeito antecedente para o resultado, demonstrando a relação de causalidade entre os mesmos.

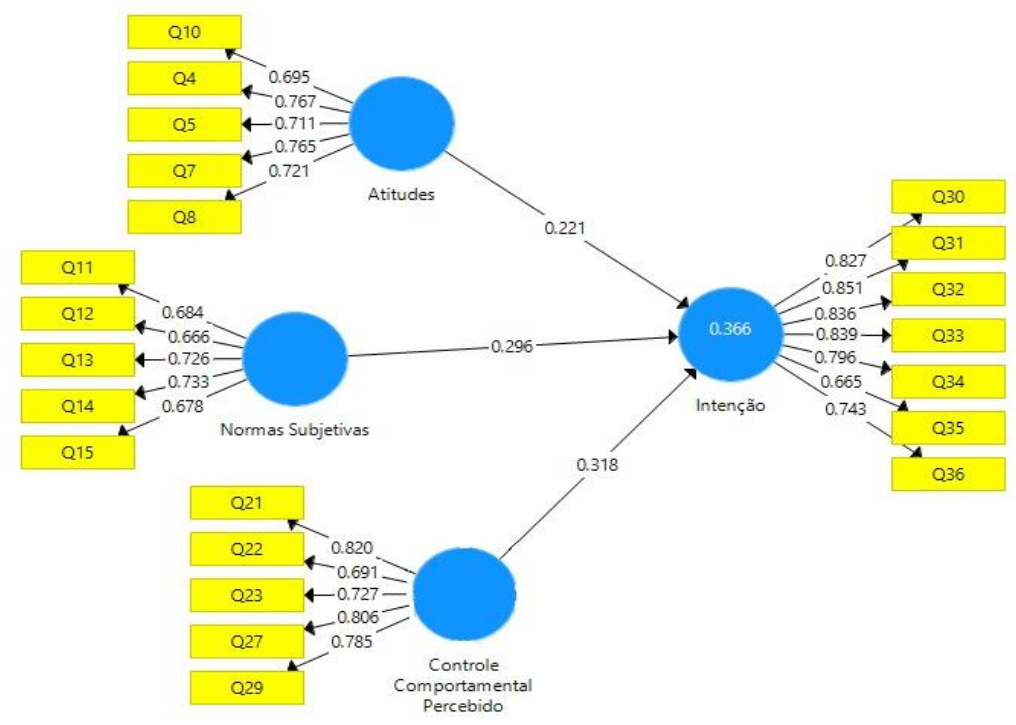

Figura 1. Diagrama de caminhos do modelo de pesquisa.

\subsubsection{Influência das atitudes, normas subjetivas e controle comportamental percebido sobre a intenção de denúncia}

Os resultados da análise quantitativa demonstraram que os construtos da TCP explicam em torno de $36 \%$ da intenção de comportamento de denúncia de problemas de acessibilidade em sítios do governo pelas pessoas com deficiência. Apesar da literatura apontar este resultado como moderado (CHIN, 1998), os resultados apresentados nesta pesquisa são importantes, considerando que não havia qualquer estudo explicando a intenção de comportamento de denúncia e físcalização de pessoas com deficiência. Esse resultado mostra que a pesquisa alcançou avanço importante, ao explicar parte da variância de tema complexo, até então pouco explorado. Entretanto, o trabalho mostra a necessidade de mais investigações na área, de forma a identificar outras características 
que podem ajudar a explicar a intenção de denúncia por pessoas com deficiência sobre a falta de acessibilidade em sítios governamentais.

Em relação ao peso de cada caminho $(\beta)$ das variáveis independentes em relação à variável dependente, o construto que teve maior peso em relação à intenção de comportamento de denúncia foi o controle comportamental percebido, seguido de normas subjetivas, e por último, atitudes.

Esse achado é relevante, tendo em vista que o controle comportamental percebido está relacionado às habilidades e outros recursos necessários para a realização do comportamento. Assim, é importante uma maior divulgação dessa temática, ensinando e capacitando as pessoas com deficiência a denunciar problemas de acessibilidade em sítios do governo. Esse achado remete ao que foi mencionado pelo promotor de justiça (PJ-03), da importância dos meios de comunicação de massa proporem a discussão desse tema, a fim de levar essa problemática ao conhecimento da sociedade. Deve-se promover o conhecimento de onde, como e para quem denunciar esse tipo de problema. Assim, saber descrever o problema de acessibilidade encontrado em sítio do governo, conhecer as leis que tratam sobre os direitos de acessibilidade Web, saber como funciona o procedimento de denúncia e ter conhecimento de onde realizar a denúncia influenciam positivamente na intenção de denúncia de pessoas com deficiência.

Observa-se que as três variáveis da TCP estão positivamente relacionadas à intenção de comportamento de denúncia de problemas de acessibilidade em sítios do governo. A relação positiva entre atitudes, normas subjetivas e controle comportamental percebido em relação à intenção de comportamento de denúncia também foi percebida no trabalho de Cheng, Lam e Hsu (2006), que identificaram a relação positiva entre os construtos da TCP e a intenção de comunicação verbal de consumidores. Semelhantemente, Seifert (2016) também observou a influência positiva das variáveis da TCP em relação à comunicação interpessoal sobre agressão sexual. Além disso, Feng e $\mathrm{Wu}$ (2005) constataram que as atitudes, normas subjetivas e controle comportamental percebido estão positivamente relacionados à intenção dos enfermeiros em relatar suspeita de abuso infantil em Taiwan.

Em relação ao peso de cada variável sobre a intenção de comportamento de denúncia, foram obtidos distintos resultados na literatura e no presente trabalho. No trabalho de Natan, Hanukayev e Fares (2011), as crenças normativas dos enfermeiros em relação à denúncia de violência cometida contra eles no local de trabalho foi a variável que obteve maior efeito sobre a intenção de relatar. Já Cheng, Lam e Hsu (2006) apontaram que o controle comportamental percebido foi o principal fator que levou à intenção negativa de comunicação verbal dos consumidores, sendo as atitudes o fator com menor peso, resultado semelhante ao obtido neste trabalho. Seifert (2016), por sua vez, identificou que a variável atitudes foi a que obteve maior efeito sobre a intenção de comunicação interpessoal de agressão sexual. Diante disso, é possível identificar diferentes resultados nos trabalhos que utilizaram a TCP para identificar a intenção de comportamento de denúncia. Uma possível explicação se refere ao distintos contextos estudados, os quais também são influenciados por fatores culturais dos diferentes países onde os estudos foram realizados.

Tendo em vista a relação positiva entre atitudes e intenção comportamental, depreende-se que quanto mais favoráveis as crenças comportamentais de pessoas com deficiência, maior será a intenção de denúncia de problemas de acessibilidade em sítios 
do governo. Esse resultado demonstra que a importância da denúncia para o indivíduo, bem como a crença em resultados desejáveis influencia positivamente na intenção de denúncia. Portanto, a hipótese de pesquisa H1 foi confirmada.

Outrossim, tendo em vista a relação positiva entre normas subjetivas e intenção comportamental, observa-se que quanto mais os grupos de referência apoiam o comportamento de denúncia e atuam denunciando essas práticas, maior o engajamento da pessoa com deficiência no comportamento de denúncia de problemas de acessibilidade em sites do governo. Portanto, a hipótese de pesquisa $\mathrm{H} 2$ foi confirmada.

Por fim, o controle comportamental percebido, que obteve a maior influência sobre a intenção de denúncia de problemas de acessibilidade em sítios do governo, também apresentou influência positiva sobre a intenção comportamental. Assim, os resultados demonstraram que quanto maior o controle comportamental percebido, maior o engajamento da pessoa com deficiência no comportamento de denúncia de problemas de acessibilidade em sítios do governo. Desse modo, a hipótese de pesquisa H3 foi confirmada.

\section{Conclusões e Trabalhos Futuros}

Este trabalho buscou compreender os fatores que influenciam na intenção de comportamento de denúncia de pessoas com deficiência em relação à falta de acessibilidade em sítios do governo. A fim de atingir o objetivo deste trabalho, diversas etapas foram realizadas. Primeiramente, foi investigada a existência de denúncias ao MPMG e à Ouvidoria Geral da União. Os resultados demonstraram evidências preliminares da inexistência de denúncias.

Outrossim, houve a realização de entrevistas com cinco pessoas com deficiência e três promotores de justiça. Essas entrevistas foram importantes para fornecer insumos para a elaboração do questionário e fornecer explicação para algumas questões que não seriam percebidas somente com a análise quantitativa. Após a análise das entrevistas, foi elaborado um questionário, baseado nos construtos da TCP e nas percepções dos entrevistados. O questionário contou com 134 respostas válidas, as quais foram analisadas descritivamente e na sequência, realizou-se a análise do modelo de equações estruturais mediante o software Smart PLS.

A análise do modelo de equações estruturais demonstrou que os construtos da TCP explicam em torno de $36 \%$ da intenção do comportamento de denúncia de problemas de acessibilidade em sítios do governo pelas pessoas com deficiência. A variável que obteve o maior peso sobre a intenção foi o controle comportamental percebido. Este, por sua vez, está relacionado às habilidades e outros recursos necessários para a realização do comportamento, como saber descrever o problema de acessibilidade, conhecer as leis relevantes sobre acessibilidade, saber como e onde realizar a denúncia.

Em relação às implicações deste trabalho, menciona-se a importância do Estado propor políticas públicas com empatia, considerando as singularidades dos cidadãos e buscando atender a todos com igualdade. Também é relevante a realização de cursos de capacitação ministrados aos promotores de justiça, aos membros dos Conselhos Municipais de Pessoas com Deficiência assim como aos servidores públicos, principalmente aqueles que trabalham nas ouvidorias. Observa-se a relevância de conscientização e capacitação dos órgãos fiscalizadores para atuarem na área. 
Destarte, é importante resgatar a confiança na eficácia da atuação da administração pública, a fim de que as pessoas com deficiência sejam incentivadas a denunciar problemas de acessibilidade em sítios do governo. Assim, é importante levar esse tema a ser discutido no meio social, destacando a importância de uma sociedade acessível e da inclusão digital de pessoas com deficiência. Acredita-se na importância da elaboração de manuais de instrução apresentando à sociedade o que é o problema de acessibilidade em sítios do governo, a importância de denunciar bem como os mecanismos de denúncia, de forma a melhor instruir os cidadãos em relação à temática. No que se refere ao governo eletrônico, observa-se que a questão da efetiva acessibilidade de sítios do governo não tem recebido a devida atenção. Assim, pesquisas futuras devem investigar os fatores que influenciam a falta de acessibilidade em sítios do governo a fim de propor melhorias para esse cenário. Por fim, este trabalho contribui com os Grandes Desafios em Interação Humano Computador na medida em que propõe a inclusão digital de pessoas com deficiência.

Como sugestão de trabalhos futuros, indica-se o refinamento do questionário a fim de tentar adequar outras questões que possam promover uma melhor explicação sobre a intenção do comportamento de denúncia analisado. Sugere-se também para trabalhos futuros que a pesquisa seja aplicada buscando maior diversidade de deficiências. Destarte, sugere-se a abordagem estendida da TCP, abordando elementos como questões culturais, emoções, gênero e outros. Também sugere-se o estudo do impacto das atividades de denúncia e fiscalização na efetiva implantação de sistemas de informação e comunicação acessíveis. Por fim, recomenda-se para trabalhos futuros a maior exploração dos resultados encontrados neste trabalho, com aprofundamento em questões importantes levantadas e levantamento de outros pontos que podem influenciar o comportamento de denúncias.

\section{Referências}

Ajzen, I. (2002). Constructing a TPB questionnaire: Conceptual and methodological considerations.

Ajzen, I. (1985). From intentions to actions: A theory of planned behavior. In Action control (pp. 11-39). Springer, Berlin, Heidelberg.

Ajzen, I. (1991). The theory of planned behavior. Organizational behavior and human decision processes, 50(2), 179-211.

Baldridge, D. C., \& Veiga, J. F. (2001). Toward a greater understanding of the willingness to request an accommodation: Can requesters' beliefs disable the Americans with Disabilities Act?. Academy of Management Review, 26(1), 85-99.

Carter, L., \& Belanger, F. (2004). The influence of perceived characteristics of innovating on e-government adoption. Electronic Journal of E-government, 2(1), 11-20.

Carvalho, V., Cagnin, M., \& Paiva, D. (2017, May). Avaliação de Acessibilidade de Web Sites de Governos Estaduais do Brasil. In Anais do XIII Simpósio Brasileiro de Sistemas de Informação (pp. 116-123). SBC.

CGI.br. (2010). Comitê Gestor da Internet no Brasil. Dimensões e características da web brasileira: um estudo do gov.br - Busca de Informação, CGI.br. Disponível em http://www.cgi.br/media/docs/publicacoes/2/cgibr-nicbr-censoweb-govbr-2010.pdf. 
Chin, Wynne W. et al. The partial least squares approach to structural equation modeling. Modern methods for business research, v. 295, n. 2, p. 295-336, 1998.

East, R. (2000). Complaining as planned behavior. Psychology \& Marketing, 17(12), 1077-1095.

Feng, J. Y., \& Wu, Y. W. B. (2005). Nurses' intention to report child abuse in Taiwan: a test of the theory of planned behavior. Research in nursing \& health, 28(4), 337-347.

Hair Jr, J. F., Hult, G. T. M., Ringle, C., \& Sarstedt, M. (2017). A primer on partial least squares structural equation modeling (PLS-SEM).

Instituto Brasileiro de Geografia e Estatística. (2010). Cartilha do censo de 2010: pessoas com deficiência. Disponível em:

<http://www.pessoacomdeficiencia.gov.br/app/sites/default/files/publicacoes/cartilh a-censo-2010-pessoas-com-deficienciareduzido.pdf >. Acesso em: 13 de jun. 2017.

Lazar, J., Goldstein, D. F., \& Taylor, A. (2015). Ensuring digital accessibility through process and policy. Morgan Kaufmann.

Maia, L. S. (2015). Uma análise preliminar da acessibilidade web dos sites de serviços de divulgação e acesso a informação pública no Brasil com base no e-mag. In: XVI Encontro Nacional de Pesquisa em Ciência da Informação. João Pessoa: UFPB.

Manning, M. (2009). The effects of subjective norms on behaviour in the theory of planned behaviour: A meta-analysis. British journal of social psychology, 48(4), 649-705

Natan, M. B., Hanukayev, A., \& Fares, S. (2011). Factors affecting Israeli nurses' reports of violence perpetrated against them in the workplace: A test of the theory of planned behaviour. International Journal of Nursing Practice, 17(2), 141-150.

Oliveira, a. D. A.; Eler, M. M. (2015). Accessibility in Electronic Government: a study on the implementation of web standards in sites gov.br. In: Proceedings of the XI Brazilian Symposium on Information System. Goiânia: UFG, Instituto de Informática. p. $691-698$.

Seifert, J. L. (2016). The Structure of Silence: applying the theory of planned behavior to college students communication about sexuality and sexual assault. Tese de dissertação de doutorado. Ohio University.

Thatcher, J. et al. (2002). Constructing acessible web sites. ed. 1. Glasshaus.

United Nations, O. (2014). United Nations E-Government Survey 2014 "E-Government for the Future We Want". New York: United Nations Department of Economic and Social Affairs.

United Nations, O. (2016). United Nations E-Government Survey 2016 "e-government in support of sustainable development". New York: United Nations Department of Economic and Social Affairs.

World Wide Web Consortium (W3C) - (2018). Web Content Accessibility Guidelines (WCAG) 2.1. W3C Recommendation 05 June 2018. Disponível em: $<$ https://www.w3.org/TR/WCAG21/>. 